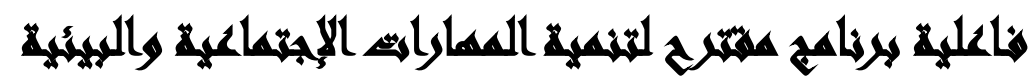

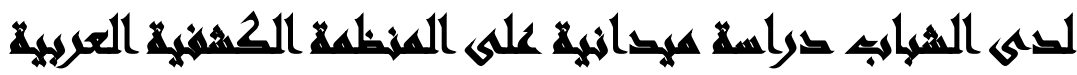

\section{[ᄉ]}

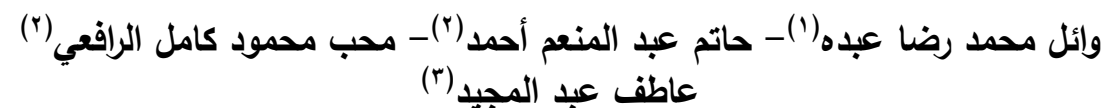

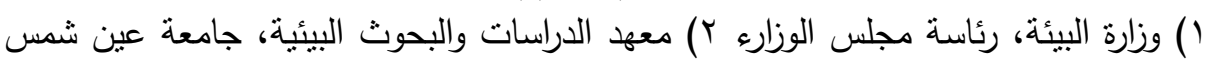

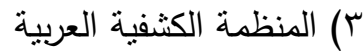

\section{المستخلئ}

هدفت الدراسة الحالية إلي نتمية المهارات الإجتماعية والبيئية لدي شباب المنظمة

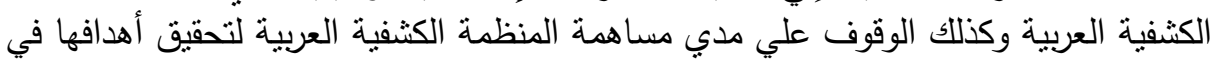

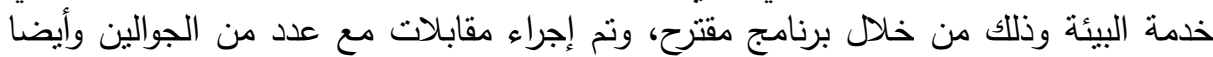

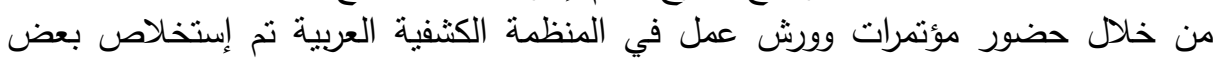

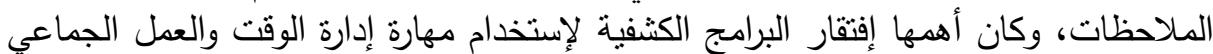

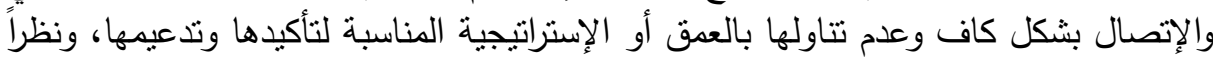

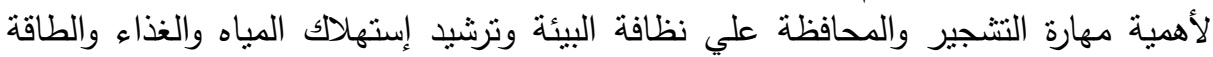



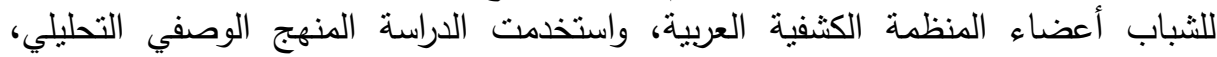

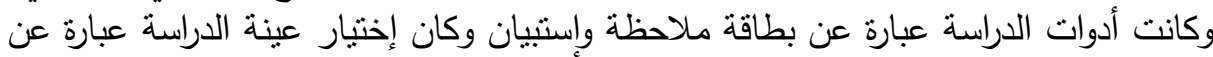

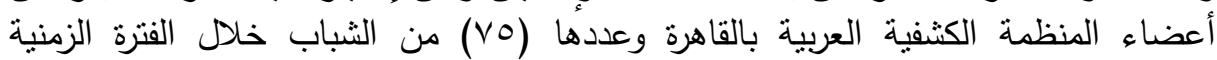
$r \cdot 11 / r \cdot 1 \mathrm{~V}$






مهارة التشجير ، والمحافظة علي نظافة البيئة وترشيد إستهلالك المياه والغذاء الغذاء والطاقة الكهربائية 




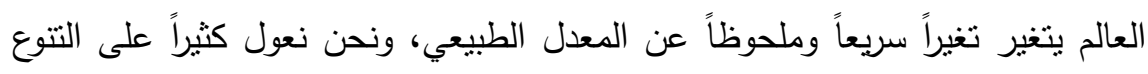

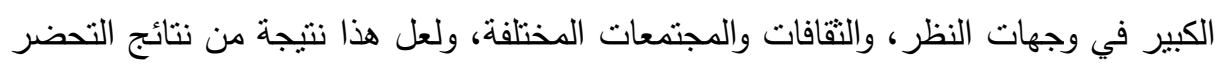

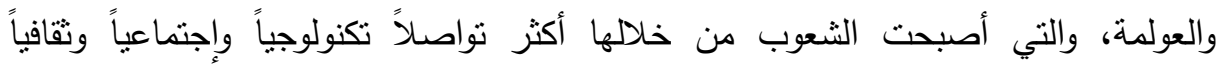



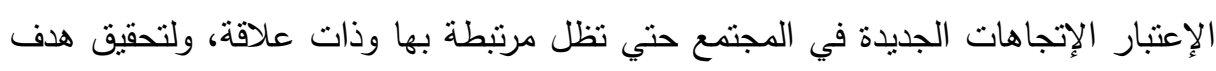

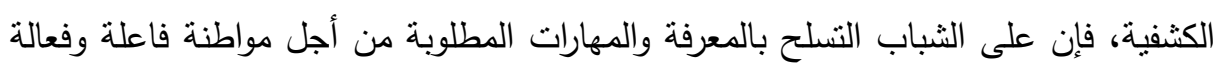

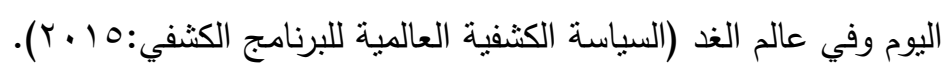

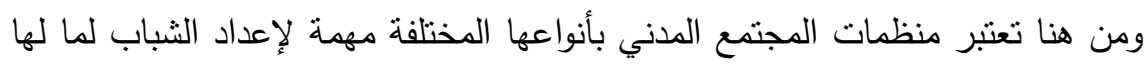



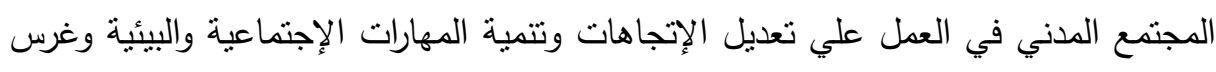

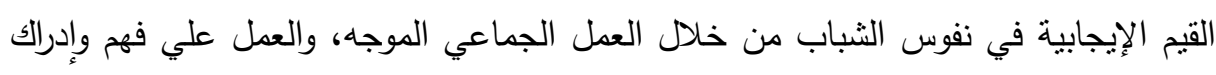

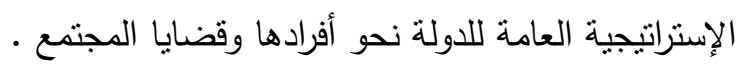



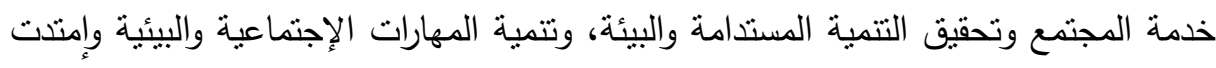

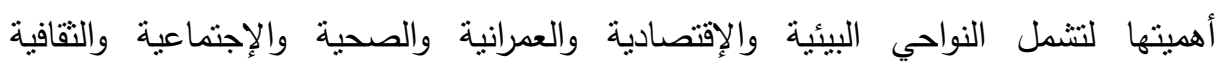

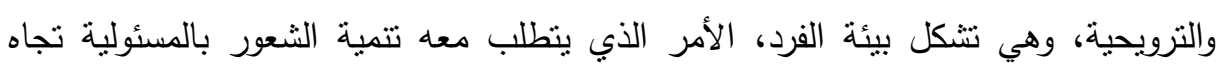



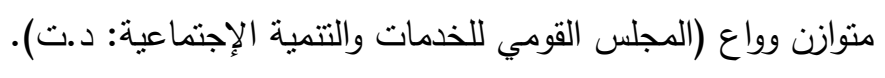



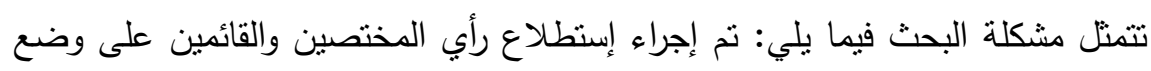

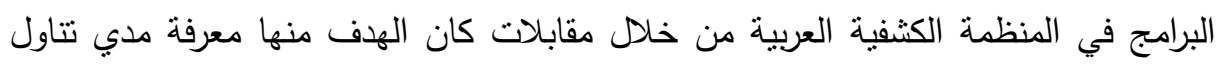



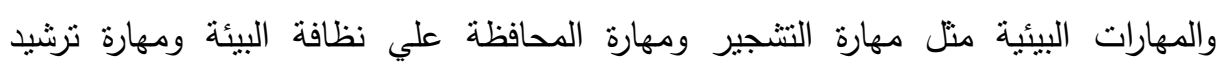

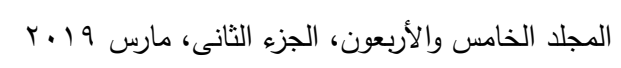


إستهلاك المياه ومهارة ترشيد إستهلاك الطاقة الكهربائية ومهارة ترشيد إستهلاك الغذاء وتم

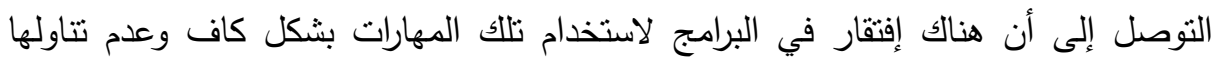
بالعمق أو بالطريقة أو الإستراتيجية المناسبة لتأكيدها وتدعيمها. كذلك من خلال مراجعة للدراسات السابقة في المجال البيئي منل دراسة (وفاء حسن بند

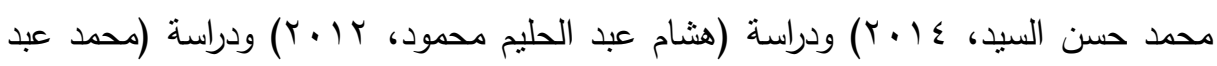


(2011,Park ,Gloria H.) تتاولت برنامج تتمية المهارات الإجتماعية والبيئية مما دعا إلي إعداد برنامج مقترح لتتمية المهارات الإجتماعية والبيئية لدي الثباب دراسة ميدانية على المنظمة الكثفية العربية. لذا تبدو الحاجة الملحة إلى إجراء دراسات تقويمية لتحديد مدي كفاءة وفاعلية برامج الإبهابه المنظمة الكثنفية العربية في إكساب أعضائها المهارات الإجتماعية والبيئية المتنوعة.

\section{أسئلا الهمهث}

يمكن صياغة مجموعة من التساؤلات تسعي الدراسة للإجابة عليها على النحو الأتي: ما فاعلية البرامج المقدمة من المنظمة الكثفية العربية في تتمية المهارات الإجتماعية والبيئية للاكور والإناث؟

ويندرج تحت هذا التساؤل مجموعة من التساؤلات الفرعية تتمثل في: 1. ما المهارات الإجتماعية والبيئية التي يجب من أن يعرفها شباب المنظمة الكثفية العربية؟

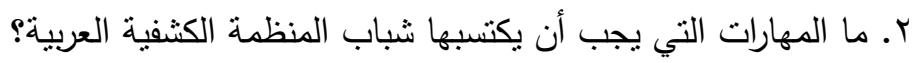

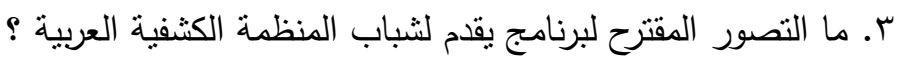

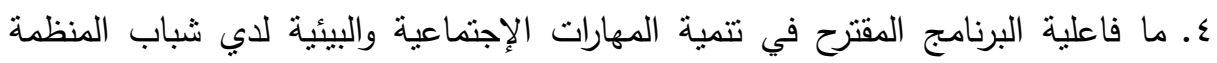
الكثفية العربية؟ 


\section{أهما اهت المهيث}

الهدف الأساسي: تتمية المهارات الإجتماعية والبيئية لدي الثباب بالمنظمة الكثفية العربية من خلال برنامج مقترح لذلك.

\section{يهاف البحث إلى تحقيق الأهداف التالية:}

أ. تقييم البرامج التي تمارسها المنظمة الكثفية العربية في تتمية المهارات. ب. التعرف على المعوقات التي تحد من فاعلية هذه البرامج.

ج. التوصل إلى نموذج مقترح لتفعيل برنامج المنظمة الكثفية العربية في تتمية المهارات. د. التعرف على آليات وأساليب المنظمة الكثفية العربية في نتمية المهارات الإجتماعية

والبيئية.

هـ الوقوف على مساهمة المنظمة الكثفية العربية في تحقيق أهدافها لخدمة البيئة بمعني غرس القيم والإتجاهات التي تساعد على بناء الفرد وإكسابه القدرة على مواجهه مشاكل

$$
\text { الحياة. }
$$

\section{هروض المهيث}

ه توجد فروق ذو دلالة إحصائية بين متوسط درجات التطبيق القبلي ومتوسط درجات التطبيق البعدي لبطاقة ملاحظات الأداء للمهارات البيئية.

ه توجد فروق ذو دلالة إحصائية بين متوسط درجات التطبيق القبلي ومتوسط درجات

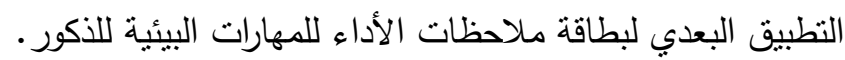

ه توجد فروق ذو دلالة إحصائية بين منوسط درجات التطبيق القبلي ومتوسط درجات التطبيق البعدي لبطاقة ملاحظات الأداء للمهارات البيئية للذكور والإناث.

ه توجد فروق ذو دلالة إحصائية بين متوسط درجات التطبيق القبلي ومتوسط درجات التطبيق البعدي لبطاقة ملاحظات الأداء للمهارات الإجتماعية. ك نوجد فروق ذو دلالة إحصائية بين متوسط درجات التطبيق القبلي ومتوسط درجات

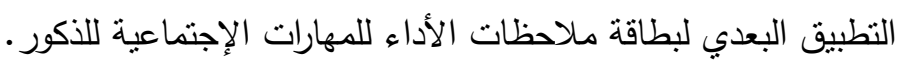

$$
\text { المجلد الخامس والأربعون، الجزء الثانى، مارس } 9 \text { ـ ب }
$$


ك توجد فروق ذو دلالة إحصائية بين متوسط درجات التطبيق القبلي ومتوسط درجات التطبيق البعدي لبطاقة ملاحظات الأداء للمهارات الإجتماعية للإناث.

\section{Aصو}

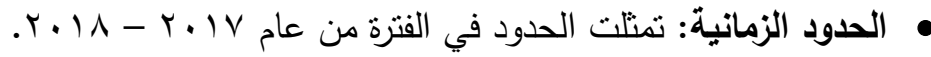

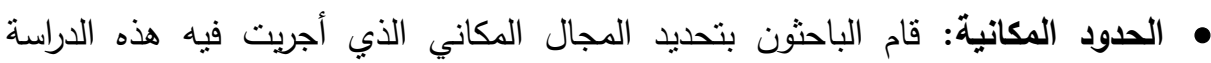
(المنظمة الكثفية العربية بالقاهرة).

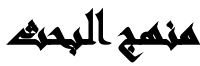

إستخدمت الدراسة المنهج الوصفي التحليلي لمناسبة طبيعة متغيرات الدراسة وكذلك تم

إستخدام المنهج شبه التجريبي لقياس تأثثر البرنامج المقترح علي تتمية الثباب بالمنظمة الكثفية العربية.

\section{أورايت الهمهي}

$$
\text { تمنلت أدوات البحث، التي نم إعدادها فيما يلي: }
$$

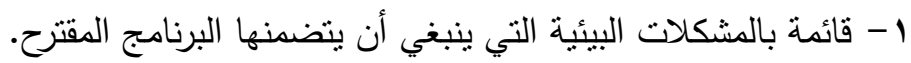

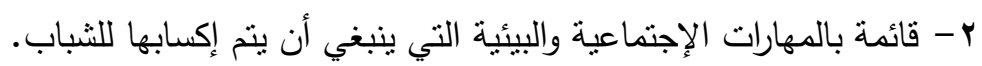

$$
\text { r- ب البرنامج المراد نطبيقة. }
$$

ع - إستنيان للتعرف علي واقع تتاول المهرات الإجتماعية والبيئية في برامج المنظمة.

$$
\text { ه- بطاقة ملاحظة الآداء للمهارات البيئية والإجتماعية. }
$$




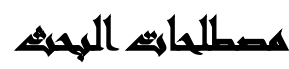

البرنامج: ويعرف البرنامج أنه كل الأفعال والسلوك والعلاقات والخبرات التي يمارسها

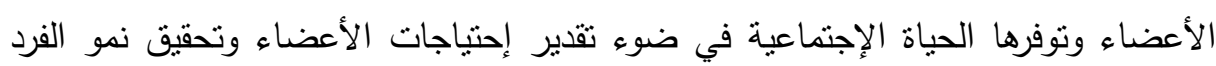

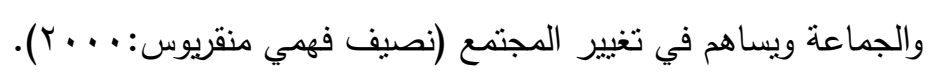

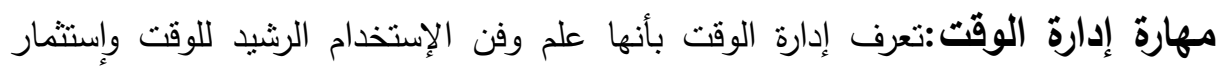

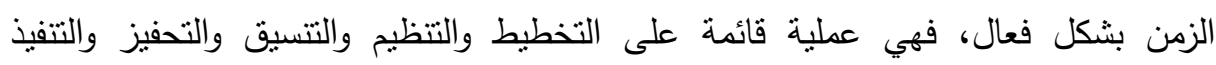
والتوجيه والمتابعة والإتصال أي أنها عملية كمية ونوعية معاً في ذاتية ذات اللحظة (مروة محمود

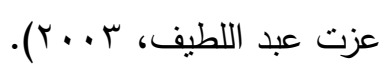

مهارة العمل الجماعي: ويعرف ي العمل الجماعي على أنه النعاون الذي يؤديه مجموعة

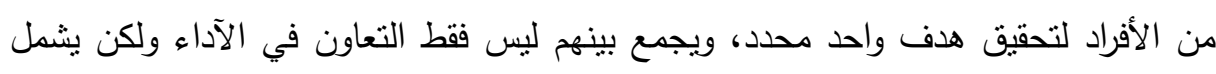



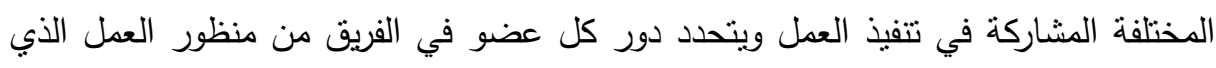

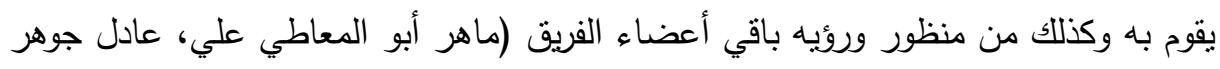

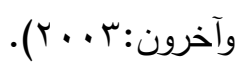

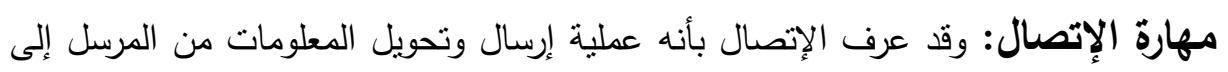

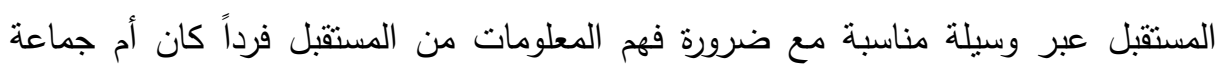

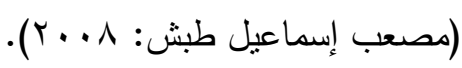

\section{إجباءايت المهمث}

أولاً: للإجابة عن السؤال الفرعي الأول" ما الدهارات الإجتماعية والبيئية التي يجب أن الهبه

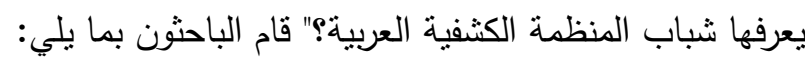

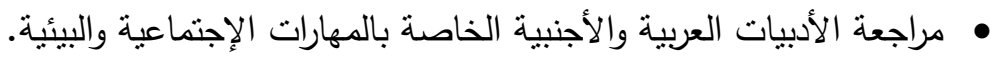

$$
\text { • • ت تحديد مفهوم المهارات الإجتماعية والبيئية. }
$$

• • وضع قائمة بالمهارات الإجتماعية والبيئية في صورتهات الأولية.

$$
\text { المجلد الخامس والأربعون، الجزء الثانى، مارس } 19 \text { ـ ب }
$$




$$
\text { • • إجراءع قاتئمة بالمهارات الإجتماعية والبيئية على مجموعة من المحكمين. }
$$

• تحديد المهارات الإجتماعية والبيئية التي يجب أن يعرفها الثباب .

• إستخدام هذه القائمة في بناء ووضع تصور لبرنامج قائم على التعلم متعدد الأبعاد لتتمية

المهارات الإجنماعية والبيئية . الباتية

$$
\text { • • إستخدام هذه القائمة في بناء مقياس. }
$$

ץ- إعداد قائمة الأبعاد في صورتها الأولية: نم إعداد قائمة بالمهارات الإجتماعية والبيئية

التي ينبغي أن يعرفها الثباب من خلال:

• مراجعة الدراسات والبحوث السابقة التي نتاولت المهارات الإجتماعية والبيئية.

$$
\text { • آراء الخبراء والمتخصصين في شئون البيئة. }
$$

•المراجع التي تتاولت مفهوم المهارات الإجتماعية والبيئية وسماتها وعناصرها وأهمية معرفة ولية

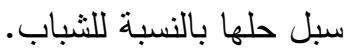

تضمنت القائمة بصيغتها الأولية مهاراتان رئيسيتان، امهارات فرعية هما:

$$
\text { • • المهارات الإجتماعية. }
$$

ץ- ضبط القائمة: تم عرض القائمة المبئية التي تم التوصل إليها على مجموعة من المحكمين من أعضاء هيئة التدريس بكليات الخدمة الإجتماعية والمنظمة الكثفية العربية وبعض المسئولين بالثقافة والتوعية البيئية بجهاز شُئون البيئة، للتعرف على آرائهم في

$$
\text { القائمة من حيث: }
$$

• ملائمة المهارات الواردة بالقائمة لطبيعة الثباب ومناسباتها وأهمية مكوناتها. • • • • ملامة المدلول اللفظي لكل بعد في القائمة.




• إنتماء المهارات الفرعية للمشكلات الرئيسية بالقائمة. وقد أجمعوا على شمول القائمة

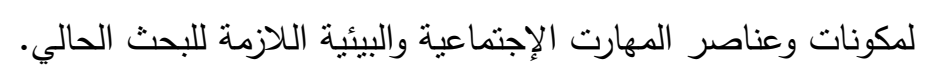

؟ - إعداد قائمة المهارات الإجتماعيةوالبيئية في صورتها النهائية: تم تعديل القائمة المبدئية في ضوء أراء المحكمين وبذللك نم التوصل إلى قائمة تحتوي على مهارات أبعاد رئيسية

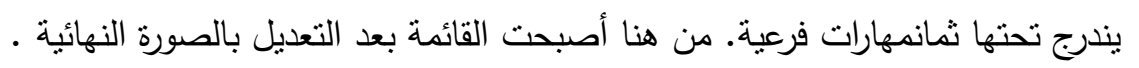

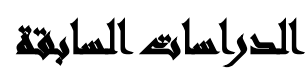

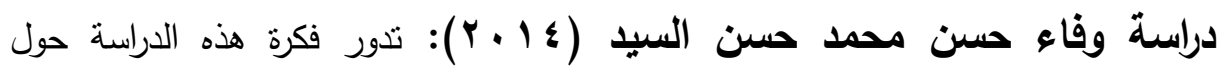
موضوع فاعلية البرامج والأنشطة الطلابية الجامعية في ضوء معايير الجودة الثاملة. أهداف الدراسة: موضوع فاعه • تحديد متطلبات جودة البرامج والأنشطة الطلابية الجامعية في ضوء معايير الجودة الثاملة.

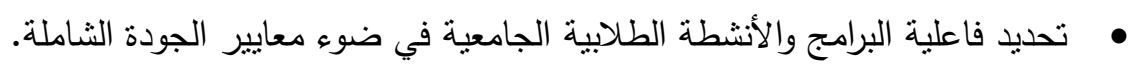

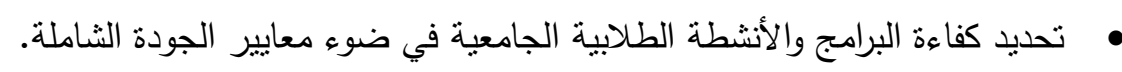

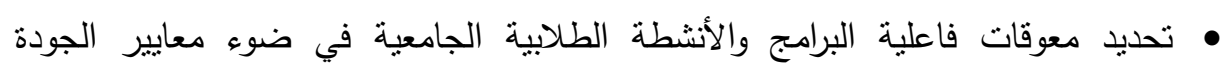
الثاملة.

• تحديد المقترحات لمواجهة المعوقات التي تحد من فاعلية البرامج والأنشطة الطلابية الجامعية في ضوء معايير الجودة الثاملة. • التوصل إلي رؤية مستقبلية لزيادة فاعلية البرامج والأنشطة الطلابية الجامعية في ضودهاء معايير الجودة الثاملة.

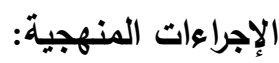

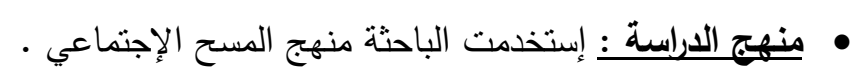


الجودة الثاملة للمستفيدين. إستمارة لقياس كفاءة المسئولين القائمين علي تتفيذ البرامج 
والأنشطة الطلابية الجامعية برعاية الثباب. دليل مقابلة شبه مقننه مطبقة علي الخبراء والمتخصصين والأكاديمين. • عينة الدراسة: عينة عشوائية منتظمة بلغ حجمها (7هب) مفردة بتطبيق قانون الحجم

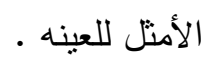

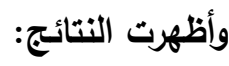
• زيادة قدرة البرامج والأنشطة الطلابية الجامعية على تقدير الإحتياجات من خلال نتوع برامج إدارة رعاية الثباب حسب الإحتياجات الفعلية للطلاب.

$$
\text { • • أن تشجع الأنشطة إبداعات الطلاب المختلفة. }
$$

• شعور الطلاب المستقيدين بالبرنامج بالتقدير عند تعاملهم مع فريق العمل بإدارة رعاية

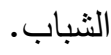

زيادة قدرة البرامج والأنشطة الطلابية الجامعية على مواجهة مشكلات المستفيدين.





• تحسن إدارة رعاية الثباب من مستوي برامجها بصفة مستمرة وتسعي إدارة رعاية الثباب الاب إلى النطوير للأفضل مستقبلاً. تساهم البرامج والأنشطة الطلابية الجامعية في مساعدة الطلاب المستفيدين على التخلي عن بعض العادات غير المرغوب فيها وتغيير سلوكياتهم إلى الأفضل. أ. أوجه الإتفاق:

• تفق هذه الدراسة مع الدراسة الحالية في الإستعانة بمنهج المسح الإجتماعي بالعينة. والإتفاق في بعض الأهداف التي تبحث فعالية تتمية المهارات لدي الثباب. ب. أوجه الإختلاف: • لكن هذه الدراسة لم تتتاول تتمية المهارات الإجتماعية والبيئية للأكور والإناث داخل المنظمة الكثفية العربية والدور الذي يقوموا به. 
تتاولت هذه الدراسة عينة عشوائية من الثباب الجامعي أما الدراسة الحالية فقد تتاولت شباب المنظمة الكثفية العربية.

$$
\begin{aligned}
& \text { دراسة هشام عبد الحليم محمود (Y I • Y): } \\
& \text { هافت الدراسة إلى: }
\end{aligned}
$$

• وضع إستراتيجية لتطوير الحركة الكثفية بدولة الإمارات العربية المتحدة وذلك من خلال التعرف على نقاط القوة والضعف والفرص والتهديدات التي يمكن أن تؤثر على الحركة الكثفية بدولة الإمارات العربية المتحدة.

$$
\text { • • الأهداف الإستراتيجة للحركة الكثفية بدولة الإمارت العربية المتحدة. }
$$$$
\text { • تقييم ومؤشرات النجاح للحركة الكثفية بدولة الإمارات العربية المتحدة. }
$$$$
\text { • دور وسائل الإعلام في نشر الحركة الكثفية في المجتمع. }
$$

• الكثف عن مقومات ومعوقات تطبيق مدخل الجدارات الوظيفية بالبنوك محل الدراسة. ويتم

$$
\text { تحقيق هذا الهدف من خلال الدراسة الميدانية. }
$$

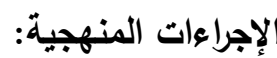

أ. منهج الارلسة: المنهج الوصفي بالإسلوب المسحي لمناسبته لطبيعة الدراسة. ب. عينة الارلسة: العاملين في المجال الكثفي بدولة الإمارات العربية المتحدة بالطريقة عمدية

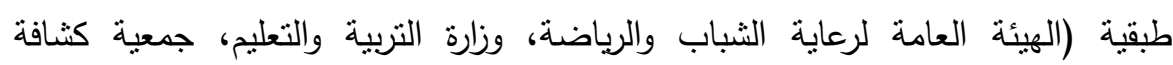

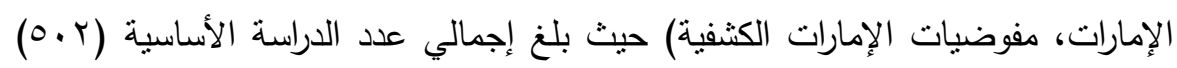

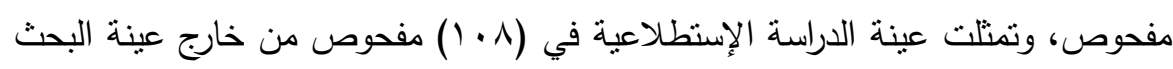
الأساسية.

وأظهرت النتائج: التوصل إلى إستراتيجية مقترحة لتطوير الحركة الكثفية بدولة الإمارات العربية المتحدة.

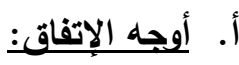

• تثقق هذه الدراسة مع الدراسة الحالية في الإستعانة بشباب المجال الكثفي في عينة الدراسة.

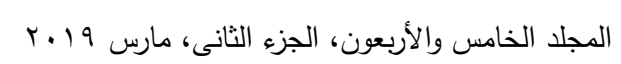




$$
\text { • ب. والإتفاق في بعض الأهداف التي تبحث تقييم تتمية المهارات لدي الثباب. }
$$

• لكن هذه الدراسة لم تتتاول تتمية المهارات الإجتماعية والبيئية للذكور والإناث داخل

المنظمة الكثنفية العربيةوإنما قامت بوضع إستراتيجية عامة. تتاولت هذه الدراسة عينة من العاملين في الدجال الكثفي بدولة الإمارات العربية المتحدة

أما الدراسة الحالية فقد تتاولت شباب المنظمة الكثنية العربية.

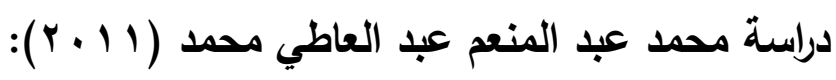



• بناء إستراتيجية مقترحة للحركة الكثفية المدرسية بجمهورية مصر العربية. • إستخلاص محكات ومعايير من القراءات النظرية الحديثة ومن الدراسات السابقة المرتبطة

$$
\text { ومن الظروف الواقعية للمجتمع. }
$$

• وضع النموذج النهائي المقترح في صورة نموذج لإستراتيجية متكاملة مستقبلية للنشاط

$$
\text { الكثفي المدرسي بجمهورية مصر العربية خلال · ل سنوات. }
$$



$$
\text { أ. منهج الاراسة: إستخدم الباحث المنهج الوصفي. }
$$

ب.عينة الدراسة: يتكون مجتمع وعينة البحث من قادة الكثافة علي مستوي الجمهورية (خبراء - موجهين مركزيين - موجهي المراحل - قادة الفرق الكثفية) وعددهم (ع ل ( ).

(النتائج:

• إتفاق جميع قيادات العينة من الموجهين المركزيين وموجهي المراحل وكذلك قادة الفرق على أن أهداف الحركة الكثنفية واضحة لديهم بشكل كافي. • غياب التسيق بين إدارة الكثافة بالوزارة والموجهين المركزيين بالمديريات التعليمية في لهي التخطيط والتتفيذ للعمل الكشفي بالوزارة. • عدم مشاركة قادة الفرق "القيادة المبانشرة" في رسم السياسات العامة للحركة. 
• أن البرامج الكثفية الحالية تحتاج إلى التطوير والتحديث لتواكب التقدم العلمي والتكنولوجي وتلبي إحتياجات الأعضاء المنتمين للحركة.

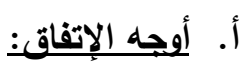

• تثقق هذه الدراسة مع الدراسة الحالية في الإستعانة بقادة الدجال الكثفي في عينة الدراسة.



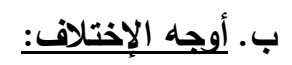
• لكن هذه الدراسة لم تنتاول تتمية المهارات الإجتماعية والبيئية للأكور والإناث داخل المنظمة الكثفية العربيةوإنما قامت بوضع إستراتيجية للحركة الكثفية المدرسية.

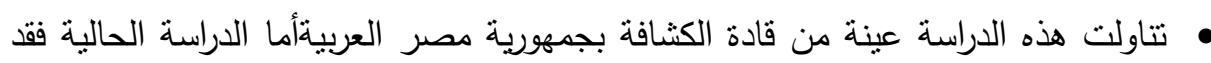
تتاولت شباب المنظمة الكثفية العربية. دراسة (Dawes, Nickki Pearce, 2011): بعنوان: معرفة الأسس النظرية البحث وتحفيز الثباب على النطوير في برامج المنظمة. أكدت الدراسة على أن الثباب يمكنه الإستفادة من العديد من الفرص التتموية التي تقدمها برامج المنظمة. كما أنه يمكن تعزيز

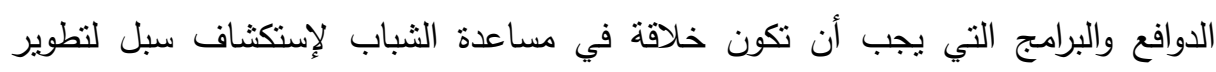
أنشطة البرنامج. دراسة ( 2011,Park ,Gloria H. ) ): بعنوان: دور النشاط اللاصيفي في تتمية مهارات الثباب الإيجابية. أشنارت هذه الدراسة إلى وصف العلاقة بين المشاركة والنشاط اللاصيفي وتتمية الثباب من الناحية الأكاديمية والنفسية والإجنماعية للثباب الموهوبين أكادية الثاديمياً.

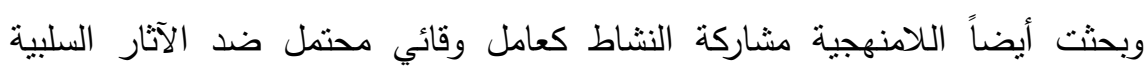

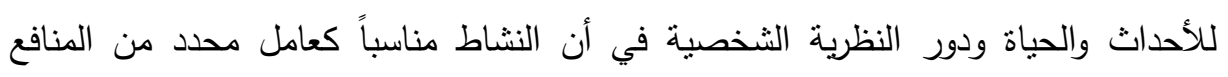
الإنمائية الإيجابية في الثباب في هذه الدراسة. دراسة (Jimenez, Agueda Parra and others, 2009): بعنوان: تعزيز التتمية الإيجابية للشباب من خلا الأنشطة اللاصيفية. أثارت أهداف هذه الدراسة إلى محاولة وضع السلوكيات المحفوفة بالمخاطر بإستخدام نهج يقوم على نموذج العجز عن صحة المراهقين

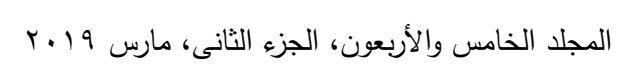


ونمائهم ويركز هذا النموذج على الكفاءة والإيجابية في تتمية الثباب. ومن أهم النتائج أن الأنشطة اللامنهجية قادرة على تعزيز التتمية للمراهقين.



يعتبر تحديد المفاهيم والمصطلحات العلمية أمراً ضرورياً في البحث العلمي عند صياغة أي مشكلة، وكلما إتسم هذا التحديد بالدقة والوضوح سهل علي القراء الذين يتابعون البحث إدرالك المعاني والأفكار التي يريد الباحث التعبير عنها دون أن يختلفوا في فهم ما يقول. وهذه المفاهيم هي: - الدرات

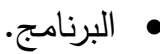

• المهارات الإجتماعية (مهارة إدارة الوقت - مهارة العمل الجماعي - مهارة الإتصال).

$$
\text { أولاً: البرنامج: يعرف بالآتي: }
$$

أ. مجموعة الأنشطة والعلاقات والتفاعلات والخبرات التي يمارسها ويقوم بها عضو المنظمة

$$
\text { الكثفية العربية. }
$$

ب.تهدف هذه الأنثطة إلي تتمية المهارات الإجتماعية لدي شباب المنظمة الكثفية العربية والتي تهدف إلي إثباع حاجاتهم ورغباتهم وتنهم في تغيير المجتمع. ج. تتفذ هذه الأنشطة من خلال المنظمة الكثفية العربية في إطار زمني محدد.


مخصصة لهذا الغرض. ويعرف أيضاً بأنه: "مجموعة الإجراءات التي تصمم لمساعدة الأفراد علي إكتساب


في تعديل سلوكهم وتتمية إمكانيتهم لصالح المؤسسة. (أحمد مصطفي خاطر ، . 999 (1). أ. هو مجموعة من الأنشطة المخططة القائمة علي تحديد دقيق للإحتياجات التدريبية للأكور

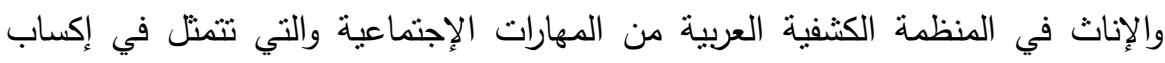
الأفراد مهارة إدارة الوقت ومهارة العمل الجماعي ومهارة الإتصال.

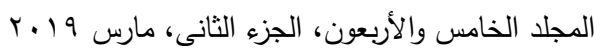


ب. تعتمد هذه الأنشطة علي تزويد أعضاء المنظمة الكثفية العربية مجموعة من المعلومات

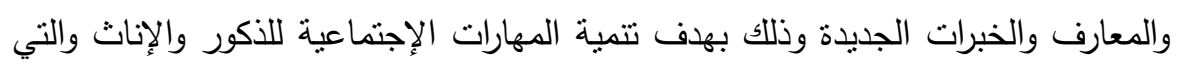

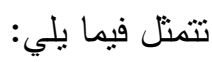

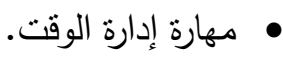

$$
\text { • مهارة العمل الجماعي. }
$$

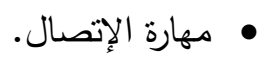

ج. يستخدم الباحث أساليب للبرنامج التدريبي منها (المحاضرة - الندوة - لعب الدور المناقثة الجماعية).

ثانياً: مفهوم المهارات الإجتماعية Social Skills: تتضمن المهارة عند تعلمها ثلاثة جوانب هي : (جانب معرفي - جانب مهاري - جانب إنفعالي) وذلك علي النحو التالي



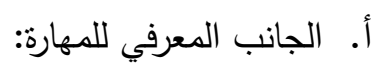

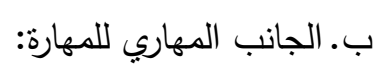

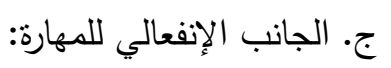

ويقصد الباحثون بالمهارات الإجتماعية في هذه الاراسة ما يلي:

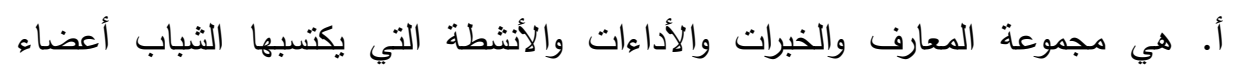
المنظمة الكثفية العربية وتتمثل في مهارة إدارة الوقت ومهارة العمل الجماعي ومهارة الإتصال، ويرجع إختيار الباحثون لهذه المهارات إلي الدراسة الإستطلاعية التي أجراها

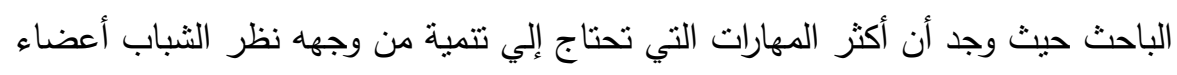
المنظمة الكثفية العربية هي تلك المهارات الثثلاثة. ب.مساعدة الثباب أعضاء المنظمة الكثفية العربية علي إدارة أوقاتهم وإستثماره الإستثمار الكهات

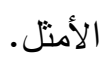
ج. مساعدة الثباب أعضاء المنظمة الكثفية العربية علي التعبير عن آرائهم وأفكارهم بحرية

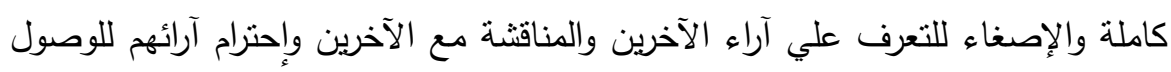
إلي قرار جماعي إيجابي يحقق أهداف المنظمة ويشبع إحتباجات أعضائها.

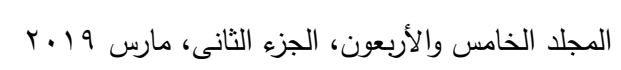


د. تعتمد هذه التغيرات علي توفير معلومات وخبرات ومهارات إجتماعية متقدمة.

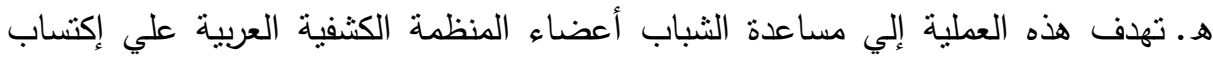
المهارات الإجتماعية المتقدمة (مهارة إدارة الوقت - مهارة العمل الجماعي - مهارة

\section{إجبراءيت الهيه}

أداة الدراسةة: تم إعداد بطاقة ملاحظة أداء المهارات الإجتماعية والبيئية في برامج المنظمة الكثفية العربية لإسنطلاع رأي الخبراء والقائمين على المنظمات الكثفية في ميدان التوعية والإرشاد البيئي للثباب حول مدي تتاول البرامج والأنشطة المقدمة لهم لفاعليات ونشـاطات عن تتمية المهارات الإجتماعية والبيئية. ومن متطلبات البحث إعداد بطاقة ملاحظة للتعرف على آداءات الثباب المشارك فئه في المنظمة الكثفية العربية من حيث المهارات الإجتماعية والبيئية. ومن الجدير بالذكر أن الباحثون عرفوا المهارات الإجنماعية إجرائياً بأنها: "هي مجموعة الإنئه

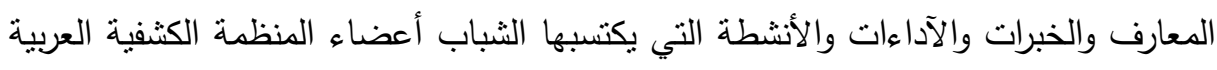
وتتمنل في مهارة إدارة الوقت ومهارة العمل الجماعي ومهارة الإتصال". وكذلك المهارات البيئية إجرائياً بأنها: "هي قدرة الفرد على إدراك المشكلات البيئية وتحديدها

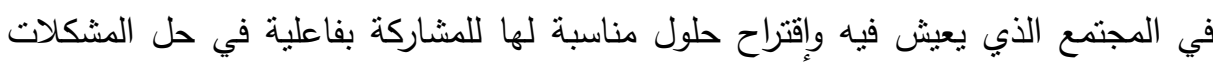

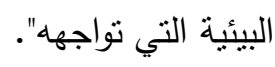
حيث تضمنت المهارات الإجتماعية والبيئية الآتي : أولاً: المهارات الإجتماعية وتتكون من:

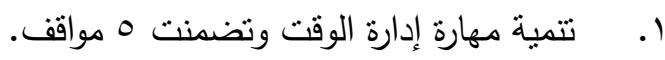
r. ت ت تمية مهارة العمل الجماعي وتضمنت ه مواقف. r. تتمية مهارة الإتصال وتضمنت مهورة مواقف. 


$$
\text { ثانياً: المهارات البيئية وتتكون من: }
$$

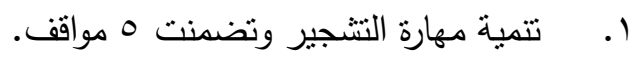
r. تتمية مهارة المحافظة علي نظافة البيئة وتضمنت م موارة مواقف.

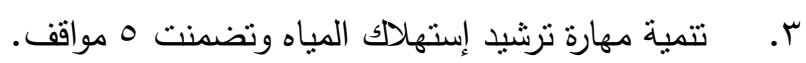

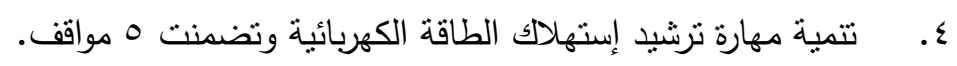


المخطط العام للبرنامج: وقد اشتمل على إجراءات إعداد وتصميم البرنامج عدداً من

$$
\begin{aligned}
& \text { الخطوات، هي: } \\
& \text { أولاً: أهداف البرنامج. } \\
& \text { ثانياً: موضوعات البرنامج الثان } \\
& \text { ثالثا: الوسائل والأدوات التعليمية. } \\
& \text { رابعا: تقويم البرنامج • }
\end{aligned}
$$

لالهيف العام للبرنامـج: تتمية المهارات الإجنماعية والبيئية لدي شباب الهنظمة الكثفية العربية.

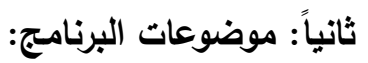 \\ وهذه الموضوعات هي:}

- الموضوع الأول: النتجير لتتقية الهواء وتحسين البيئة. - الموضوع الثاني: تحسين حالة البيئة وحمايتها من الملوثات. - الموضوع الثالث: ترشيد استهلاك موارد البيئة والعمل على استدامتها. - الموضوع الرابع : سخونة الهواء وتباين درجة الحرارة على سطح الأرض. - الموضوع الخامس: الضغط الجوى والرياح والتيارات المائية. - الموضوع السادس : الطقس . 
أ- تخطيط الوحلدة: تم تخطيط الوحدة المقترحة للبرنامج بعد التعديل الذي اقترحه المحكمون

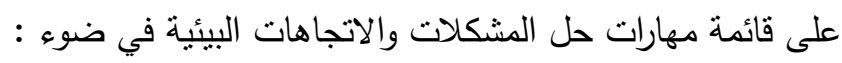

$$
\text { ا بـ الأهداف السابق عرضها. }
$$

r. مراعاة تحديد أهداف الوحدة والمهارة المتضمنة بالمحتوى وإستراتيجية التدريس بدقة ووضوح وأن تكون قابلة للقياس

$$
\text { ب- طرق التلربيس: }
$$


- نطبيق عملي على زراعة الاشجار - محاضرة عن أهمية زراعة الاسطح. - نطبيق عملي عن زراعة اسطح مراكز الثباب والمدارس المحيطة. - - محاضرة عن ملوثات المياه - تطبيق عملي لنتظيف المجاري المائية من الملوثات. - محاضرة عن ملوثات التربة. - نطبيق عملي عن إعادة تدوير مخلفات الغذاء. مداه. - محاضرة عن ترشيد استهلاك المياه. - تطبيق عملي تجربة عملية لتقليل مياه صندوق طرد المياه بدورة المياه. - - محاضرة عن الطاقة النظيفة. - نطبيق عملي عن تغير اللمبات العادية بلمبات ليد موفرة. - محاضرة عن إدارة الوقت وتطبيق عملي. - محاضرة عن العمل الجماعي وتطبيق عملي. - محاضرة عن الإتصال وتطبيق عملي.

ثُالثاً: الوسائل والأدوات التعليمية المستخدمة لأنشطة البرنيامجي: عندئ تقديم البرنامج تم مراعاة

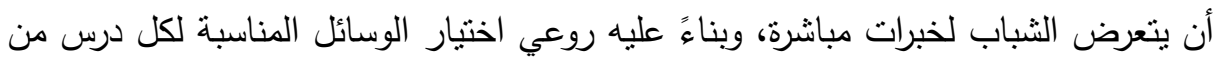


موضوعات الوحدة، مع مراعاة مناسبتها للأهداف المراد تحقيقها وكذلك ارتباطها بالبيئة المحيطة.

رابعاً:التقويم النهائي للبرنامـج: ويتم ذلك من خلال تطبيق أدوات البحث بطاقة ملاحظة أداء

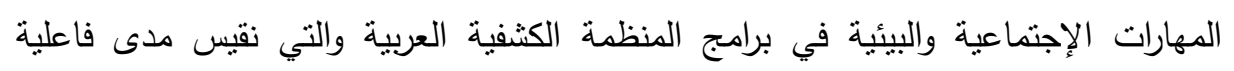
البرنامج لتتمية مهارة إدارة الوقت ومهارة العمل الجماعي ومهارة الإتصال والتهات والمهارات البيئية

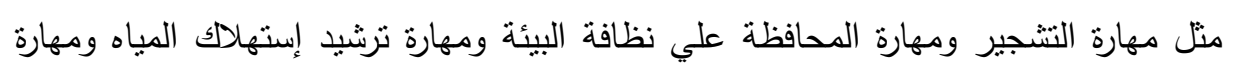
ترشيد إستهلاك الطاقة الكهربائية ومهارة ترشيد إستهلاك الغذاء لاى مجموعة البحث

(المجموعة التجريبية). خامساً: ضبط البرنامج والتأكد من صلاحيته: بعد الانتهاء من إعداد البرنامج، تم ضبطه عن

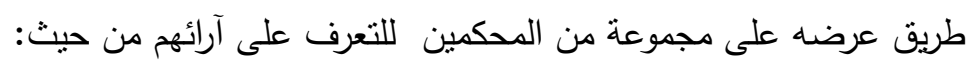
1-مدى تطابق المادة التعليمية المتضمنة في محتوى البرنامج مع الأهداف المرجو تحقيقها.

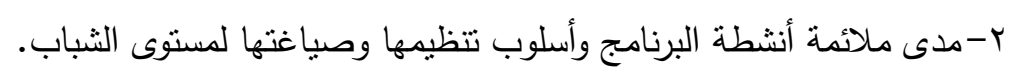
r-مدى إرتباط الأهداف التدريسية بموضوعات الوحدة. ع-مدي صحة إجراءات التدريس من أجل تحقيق أهداف كل درس. 0-مناسبة الصياغة اللغوية، وطريقة الثرح لمستوي الثباب.

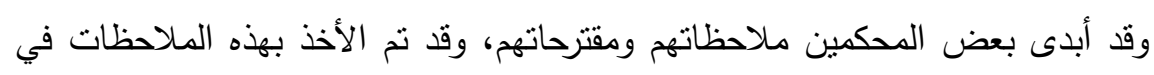

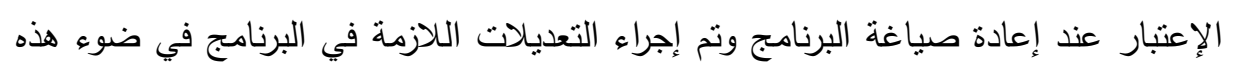

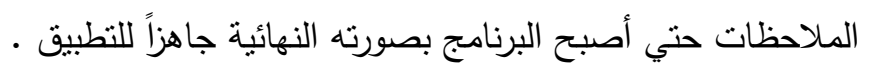

\section{Anding}

المجال المكاني: وقد قام الباحثون بتحديد المجال المكاني الذي أجريت فيه هذه الدراسة (المنظمة الكثنفية العربية بالقاهرة). وقد نم إختيار هذ المكان لعدة أسباب وهي: • وجود نشاط ملحوظ لأنشطة البيئة في المنظمة الكثفية العربية. 
• مشاركة الباحث في إلقاء بعض الندوات التي تضمنتها أنشطة البيئة داخل المنظمة الكثفية العربية. • وجود إقبال ملحوظ من الثباب للمشاركة في هذه الأنشطة. المجال البشري: يتمنل المجال البشري في (عينة عمديه غير متجانسة) من شباب (المنظمة الكثنفية العربية) تتوافر فيها الثروط التالية:

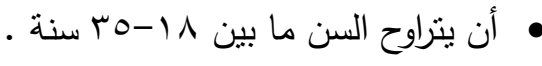
• أن يكون من الحاصلين علي مؤهل متوسط أو فوق منوسط أو عالين • عالي. • أن بكون من المترددين علي هذا المكان.

إقتصر البحث على عينة عمديه من أعضاء المنظمة الكثفية العربية بعدد ه V مفردة موزعين

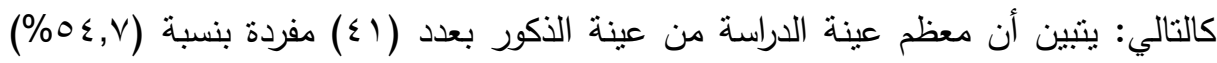

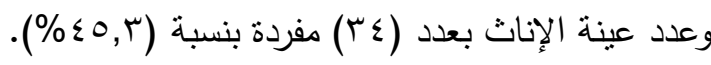

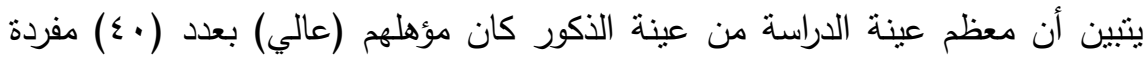

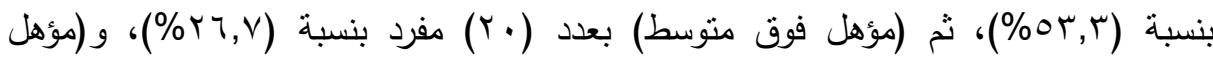


$.(\%\urcorner, \Pi)$

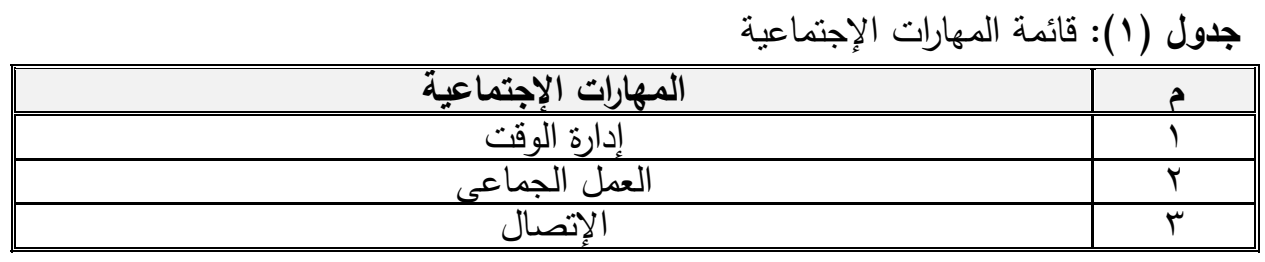

جدول (r): قائمة المهارات البيئية

\begin{tabular}{|c|c|}
\hline المهارات الإجتماعية & 5 \\
\hline التشجير & 1 \\
\hline الدحافظة على نظافة البيئة & $r$ \\
\hline ترشيد إستهلالك المياه & $r$ \\
\hline ترشيد إستهلاك الطاقة الكهربائية & $\varepsilon$ \\
\hline ترشيد إستهلاك الغذاء & 0 \\
\hline
\end{tabular}




\section{اختبار الثبات وصدق الإتساق الداخلي:}

ا. اختبار الثبات من خلال معامل ألفا كرونباخ CronbachsAlpha لاختبار ثنات عبارات الأسبات

$$
\text { الاستبيان. }
$$

r. اختبار صدق الإتساق الداخلي من خلال معامل إرتباط بيرسون بين أبعاد الاستبيان

$$
\text { وإجمالي الاستبيان. }
$$

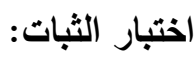

\begin{tabular}{|c|c|c|}
\hline قيمة آلفا & عدد العبارات & المتغيرات \\
\hline$\cdot, \vee \vee \vee O$ & 0 & زراعة آثُجار وحدائق نباتية \\
\hline$\cdot, \wedge \leq \leqslant$ & 0 & زراعة أسطح بدون تربة فوق المباني \\
\hline$\cdot, 0.7$ & 0 & حماية المياه من التلوث \\
\hline$\cdot, 01 \mathrm{~V}$ & 0 & حماية التربة من التلوث \\
\hline$\cdot, 71 \mu$ & 0 & الموردالمائيوأهميتةرشيده \\
\hline$\cdot, 0 \mathrm{VV}$ & 0 & ترشبد الطاقة الكهربائية \\
\hline$\cdot, 9 \cdots$ & r. & إجمالى الآداء للمهارات البيئية \\
\hline
\end{tabular}

جدول (r): ثبات محور لبطاقة ملاحظات الأداء للمهارات البيئية

يتضح من الجدول السابق أن قيم معاملات الثبات جميعها قيم جيدة حيث بلغت لادية قيم



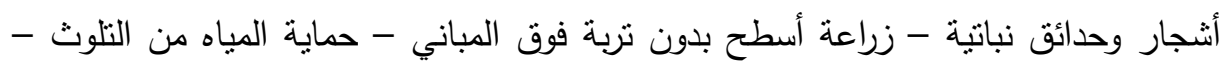

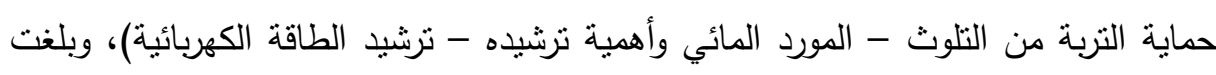

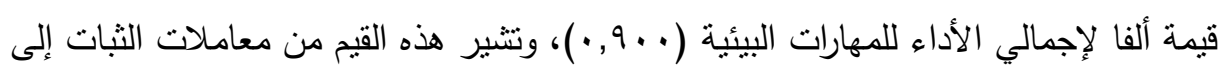

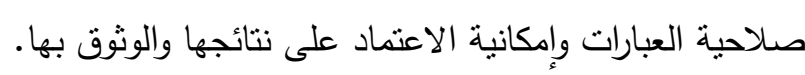



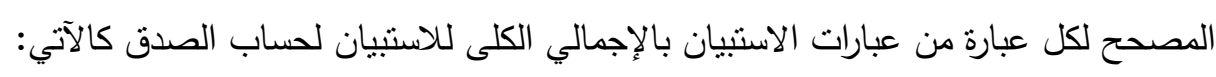


جدول ( ؛): صدق الإتساق الداخلي لبطاقة ملاحظات الأداء للمهارات البيئية

\begin{tabular}{|c|c|}
\hline معامل إرتباط بيرسون & آبعاد الإستبيان \\
\hline$\cdot, \wedge 7 \mu$ & زراعة آثجار وحدائق نباتية \\
\hline  & زراعة أسطح بدون تربة فوق المباني \\
\hline$\cdot, \mathrm{V} \leqslant \varepsilon$ & حماية المياه من التلوث \\
\hline$\cdot, \vee \vee \uparrow$ & حماية التربة من التلوث \\
\hline$\cdot$, • А५. & المورد المائي وآهمية ترشيده \\
\hline$\cdot, \mathrm{V} \leqslant \Lambda$ & ترشيد الطاقة الكهربائية \\
\hline
\end{tabular}

يتضح من الجدول السابق لصدق الإتساق الداخلي لمتغيرات المقاييس أن معاملات

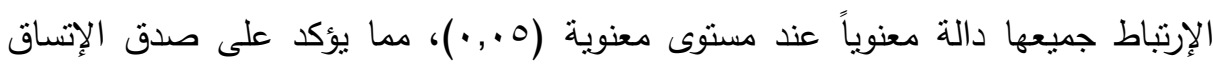
الداخلي لمتغيرات المقاييس وصداحيتها للنطبيق.

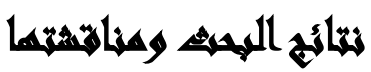

إختبار صحة الفروض:

الفرض الأول: نوجد فروق ذو دلالة إحصائية بين متوسط درجات التطبيق القبلي ومنوسط درجات النطبيق البعدي لبطاقة ملاحظات الأداء للمهارات البيئية. 
جدول (0): إختبار (ت) (t-test) لحساب الفروق بين متوسط درجات النطبيق القبلي ومتوسط درجات التطبيق البعدي لبطاقة ملاحظات الأداء للمهارات البيئية

\begin{tabular}{|c|c|c|c|c|c|c|c|c|c|}
\hline \multirow[t]{2}{*}{ قيمة d } & \multirow[t]{2}{*}{ ايتا r } & \multirow{2}{*}{ مستوى } & \multirow{2}{*}{ " تيمـة " } & \multicolumn{2}{|c|}{  } & \multicolumn{2}{|c|}{ 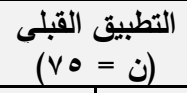 } & \multirow{2}{*}{ الكلية } & \multirow[t]{2}{*}{ المقياس } \\
\hline & & & & $\varepsilon$ & 5 & $\varepsilon$ & s & & \\
\hline$\cdot, \wedge \cdot \wedge$ & $\cdot, 70 \mathrm{r}$ & $\cdot, \cdots 1$ & $|\wedge, \vee| \vee$ & r & $\{, \varepsilon 1$ & $1,1 \pi$ & $1,7$. & 0 & ؤنجارار \\
\hline$\cdot, \wedge \backslash \leq$ & אדרו, & $\cdot, \cdots 1$ & IT,r & $1, r_{0}$ & $r, q 1$ & $1, \ldots$ & $\cdot, \vee 0$ & 0 & بدون تربح \\
\hline 9דו, & $\cdot, \varepsilon \cdot q$ & $\cdot, \cdots l$ & 9,179 & $\cdot, 10$ & $r, \cdot \Lambda$ & $\cdot, V r$ & $1, V V$ & 0 & المياه من التلوث \\
\hline$\cdot, T \wedge r$ & $\cdot, \leqslant 70$ & $\cdot, \cdots 1$ & $11, Y 11$ & $1, \cdot \varepsilon$ & $r, 9 V$ & $\cdot, V r$ & ו, & 0 & التربة مناية \\
\hline$\cdot, \vee \circ 9$ &., $0 \vee 7$ & $\cdot, \cdots 1$ & $10,1 Y \wedge$ & $1, \cdot 1$ & $r, 9 \vee$ & $\cdot, \wedge \varepsilon$ & $1, V r$ & 0 & ترأهيّة \\
\hline$\cdot, V \leq T$ & $\cdot, 007$ & $\cdot, \cdots 1$ & $1 r, 99 \wedge$ & $\cdot, \wedge \uparrow$ & $r, 70$ & $1, \cdot 7$ & 1,01 & 0 & الكرشية \\
\hline$\cdot, 9 Y \leq$ & $\cdot, \wedge 0 \leqslant$ & $\cdot, \cdots$ & $r \cdot, 0 \wedge V$ & $r, \Gamma$ & $r, \ldots$ & $r, 11$ & $\Lambda, T \vee$ & $r$. & 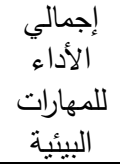 \\
\hline
\end{tabular}

يتضح من الجدول السابق للفروق بين منوسط درجات النطبيق القبلي ومتوسط درجات



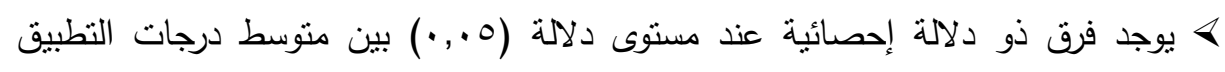

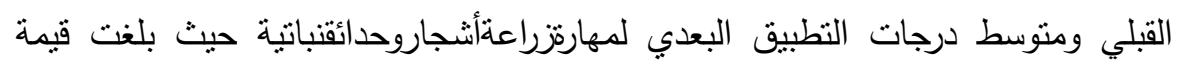




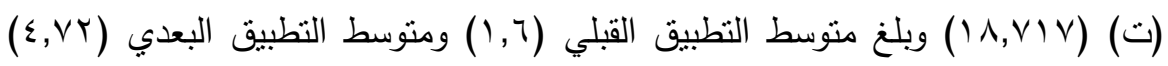

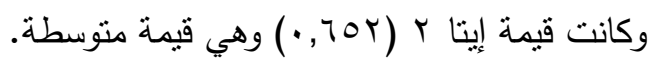

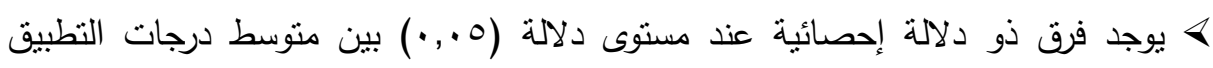



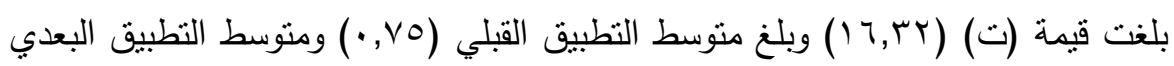

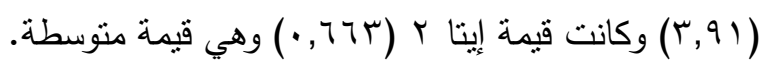



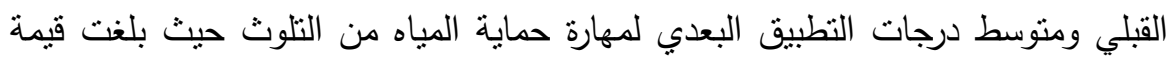

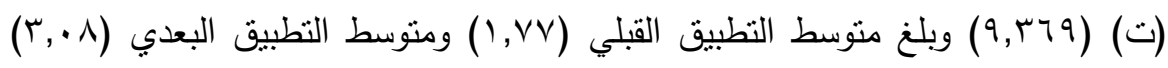

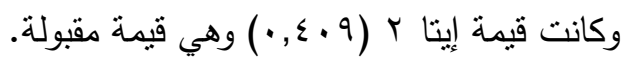
ك يوجد فرق ذو دلالة إحصائية عند مستوى دلالة (0., •) بين متوسط درجات التطبيق القبلي ومنوسط درجات التطبيق البعدي لمهارة حماية التربة من التلوث حيث بلغت دئه

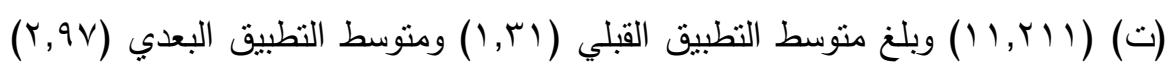

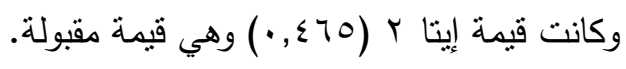
ك يوجد فرق ذو دلالة إحصائية عند مستوى دلالة (0., •) بين منوسط درجات التطبيق

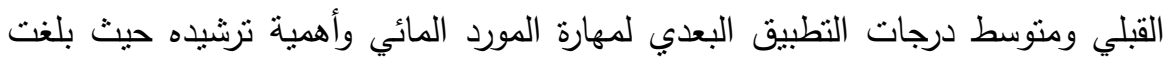

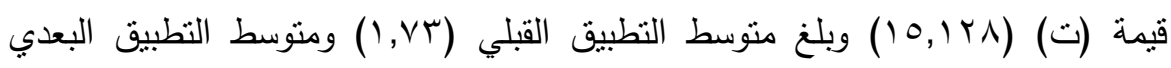

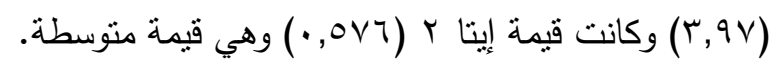

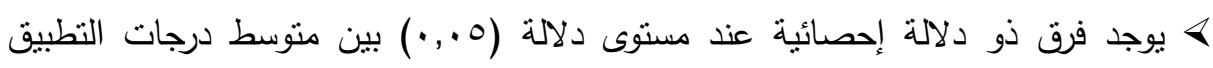

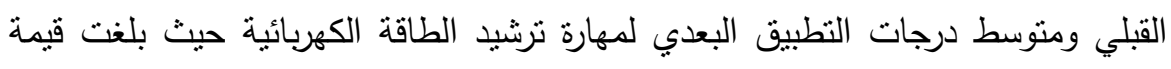

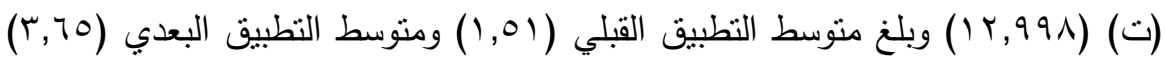

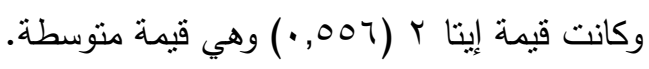



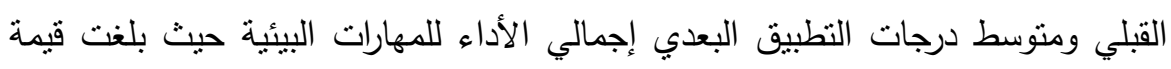






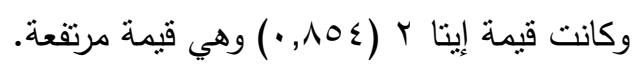

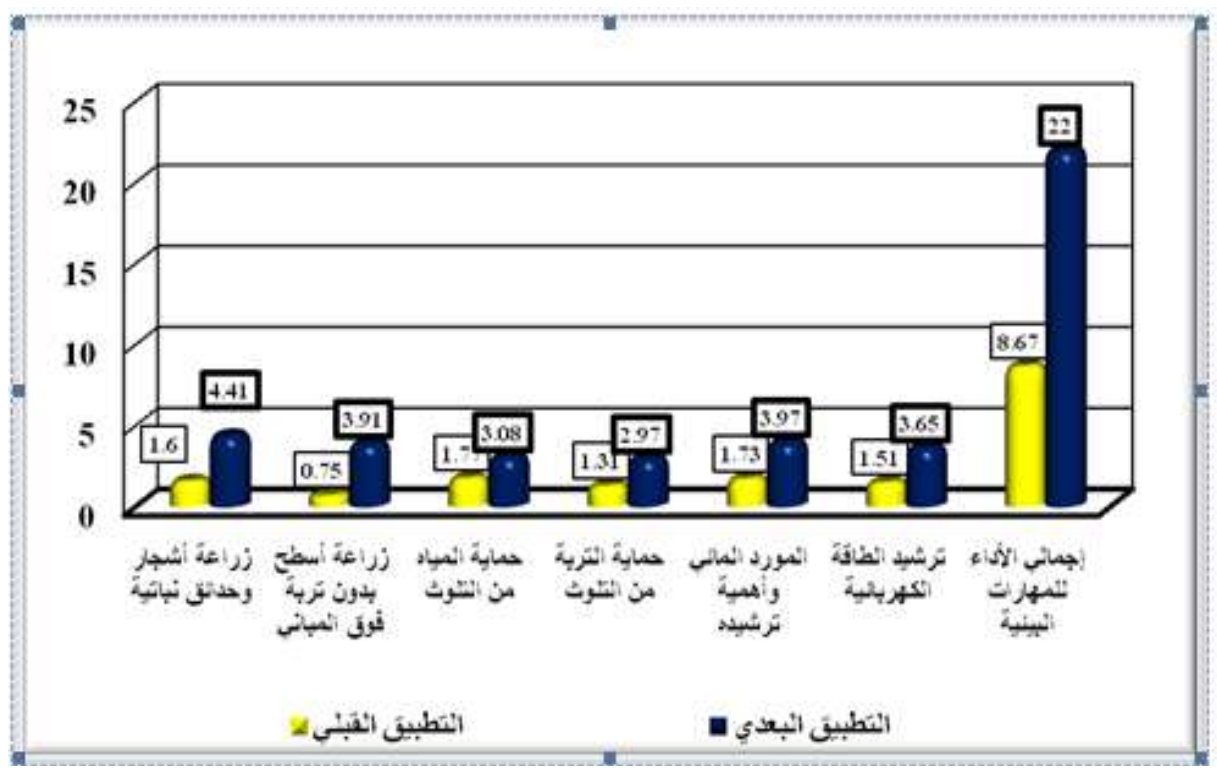

شكل (1): يوضح الفروق بين متوسط درجات التطبيق القبلي ومنوسط درجات التطبيق البعدي لبطاقة ملاحظات الأداء للمهارات البيئية

من النتائج السابقة تبين صحة الفرض الأول: نوجد فروق ذو دلالة إحصائية بين منوسط الادئ درجات التطبيق القبلي ومنوسط درجات التطبيق البعدي لبطاقة ملاحظات الأداء للمهارات البيئية.

الفرض الثاني: نوجد فروف ذو دلالة إحصائية بين متوسط درجات التطبيق القبلي ومتوسط درجات النطبيق البعدي لبطاقة ملاحظات الأداء للمهارات البيئية للاكور . 
جدول (†): إختبار (ت) (t-test) لحساب الفروق بين منوسط درجات التطبيق القبلي ومتوسط درجات التطبيق البعدي لبطاقة ملاحظات الأداء للمهارات البيئية لعينة

\begin{tabular}{|c|c|c|c|c|c|c|c|c|c|}
\hline & & & & & & & & & \\
\hline \multirow[t]{2}{*}{ قيمة d } & \multirow{2}{*}{ ايتا r } & \multirow{2}{*}{ مستوى } & \multirow{2}{*}{ " تيمة " } & \multicolumn{2}{|c|}{  } & \multicolumn{2}{|c|}{ 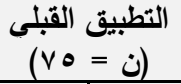 } & \multirow{2}{*}{ الكلية } & \multirow{2}{*}{ المقياس } \\
\hline & & & & $\varepsilon$ & م & $\varepsilon$ & 5 & & \\
\hline$\cdot, \vee \vee 97$ & אזד, . & $\cdot, \cdots 1$ & $1 \leq, 9 \wedge 9$ & $\cdot, \wedge \vee$ & $\varepsilon$, ro & $1, Y_{1}$ & $1, \vee 9$ & 0 & زراعة أشجار \\
\hline$\cdot, \wedge$ ᄉᄉ & $\cdot, V \cdot r$ & $\cdot, \cdots 1$ & גו & $1, r V$ & $\varepsilon, \cdots$ & $1, .0$ & אד, • & 0 & زبرون تربة أسطح \\
\hline سגד & $\cdot, \leq 77$ & $\cdot, \cdots 1$ & $\vee, I V 7$ & $\cdot, 91$ & $r, 19$ & $\cdot, T V$ & $1, \vee 99$ & 0 & من التلوث المياه \\
\hline סדו, . & $\cdot, \varepsilon \cdot \varepsilon$ & $\cdot, \cdots 1$ & А,А। & $1, .0$ & $r, 19$ & $\cdot, \nabla T$ & V & 0 & حماية التربة \\
\hline$\cdot, \vee \vee \wedge$ &., 09. & $\cdot, \cdots$ & 15,000 & $1, .7$ & $\varepsilon, .9$ & $\cdot, 94$ & 1,70 & 0 & وأهمية ترشيده المائي \\
\hline$\cdot, \vee \vee \neg$. & $\cdot, 0 \vee \wedge$ & $\cdot, \cdots 1$ & 9,900 & $\cdot, 9$. & $r, v \leq$ & 1,1 . & $1, \leqslant V$ & 0 & ترشيد الطاقة \\
\hline ש & •, ᄉ० & $\cdot, \cdots 1$ & $r \varepsilon, V V V$ & r, $\Sigma 1$ & TY,OT & $r, Y V$ & $\wedge, \vee$. & r. & اللمالي الأداء \\
\hline
\end{tabular}

يتضح من الجدول السابق للفروق بين متوسط درجات التطبيق القبلي ومتوسط درجات

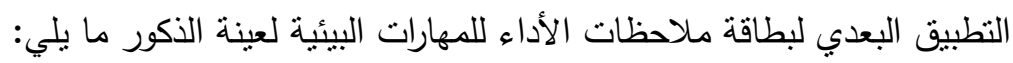
ك يوجد فرق ذو دلالة إحصائية عند مستوى دلالة (0.,.) بين منوسط درجات التطبيق القبلي ومنوسط درجات التطبيق البعدي لمهارة زراعة أثجار وحدائق نباتية حيث بلغت




ه يوجد فرق ذو دلالة إحصائية عند مستوى دلالة (0.,.) بين منوسط درجات التطبيق






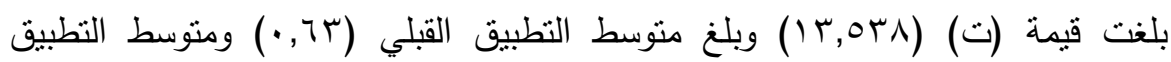

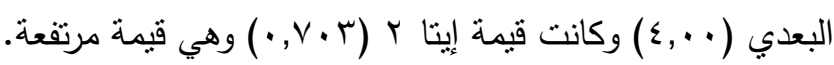



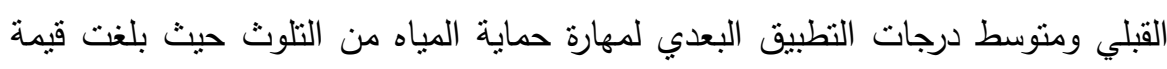

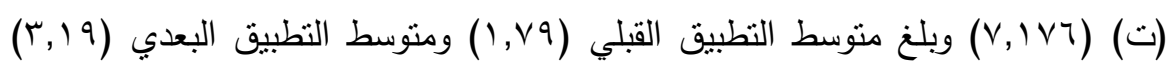



كا يوجد فرق ذو دلالة إحصائية عند مستوى دلالة (0., •) بين منوسط درجات التطبيق

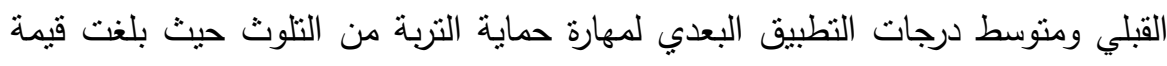

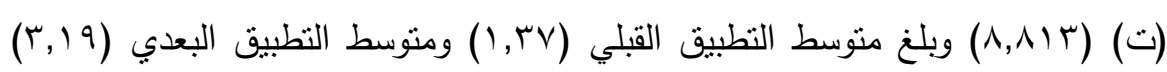

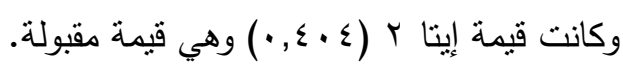
ه يوجد فرق ذو دلالة إحصائية عند مستوى دلالة (0., (•) بين متوسط درجات التطبيق


قيمة (ت) (1,000) وبلغ منوسط النطبيق القبلي (1,70) ومنوسط النطبيق البعدي




القبلي ومنوسط درجات النطبيق البعدي لمهارة ترشيد الطاقة الكهربائية حيث بلغت قيمة

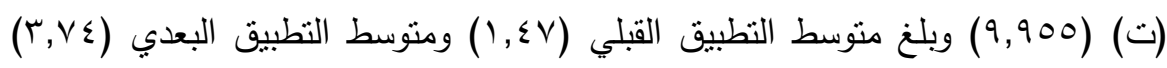

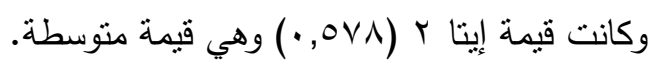

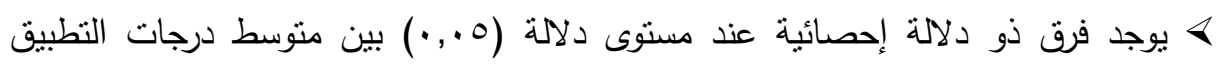

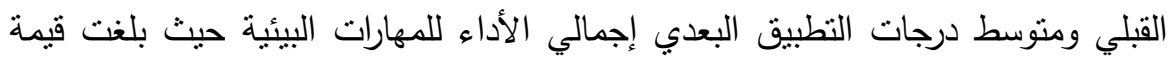

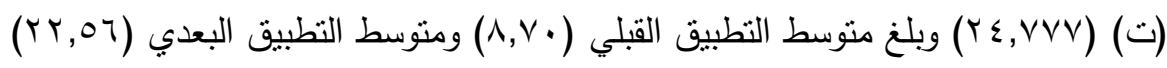

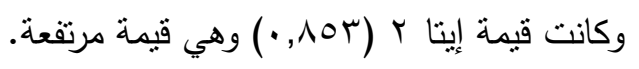






شكل (ץ): يوضح الفروق بين متوسط درجات التطبيق القبلي ومنوسط درجات النطبيق البعدي لبطاقة ملاحظات الأداء للمهارات البيئية لعينة الذكور

من النتائج السابقة تنين صحة الفرض الثاني: توجد فروق ذو دلالة إحصائية بين متوسط درجات التطبيق القبلي ومتوسط درجات التطبيق البعدي لبطاقة ملاحظات الأداء

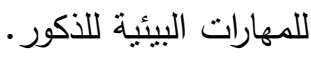


جدول (V): إختبار (ت) لحساب الفروق بين منوسط درجات النطبيق القبلي ومتوسط درجات التطبيث البعدي لبطاقة ملاحظات الأداء للمهارات البيئية لعينة الإناث

\begin{tabular}{|c|c|c|c|c|c|c|c|c|c|}
\hline \multirow[t]{2}{*}{ قيمة d } & \multirow[t]{2}{*}{ ايتا r } & \multirow{2}{*}{ مستوى الدلالة } & \multirow{2}{*}{ " تيمة " } & \multicolumn{2}{|c|}{ 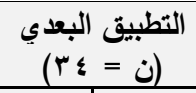 } & \multicolumn{2}{|c|}{ التطبيق القبلى } & \multirow{2}{*}{ الاليجة } & \multirow[t]{2}{*}{ المقياس } \\
\hline & & & & $\varepsilon$ & 5 & $\varepsilon$ & 5 & & \\
\hline •, Аঙq & $\cdot, V \cdot \varepsilon$ & $\cdot, \cdots l$ & $|r, r| 7$ & $1, \cdot r$ & $\varepsilon, 0$. & $\cdot, 9 \vee$ & $1, r \varepsilon$ & 0 & زراعة أشجار \\
\hline •, VA & זוד, & $\cdot, \cdots 1$ & $9, \leqslant 77$ & $1, r \leq$ & r,vA & •, 94 & $\cdot, 91$ & 0 & زبرون تربة أسطح \\
\hline$\cdot, 7 \cdot 9$ & $\cdot, r V I$ & $\cdot, \ldots l$ & 0,999 & זTד, & $r, q \leq$ & $\cdot, \wedge$. & $1, \times 0$ & 0 & من التلوث المياه \\
\hline , & $\cdot, 0 \leqslant r$ & $\cdot, \cdots 1$ & $7,9 \vee 7$ & $\cdot, 9 \vee$ & $r, 79$ & $\cdot, \times 1$ & I, Tr & 0 & من التلوث التربة \\
\hline$\cdot, V \leq V$ &., $00 \mathrm{~V}$ & $\cdot, \ldots l$ & $\wedge, \cdot \vee \diamond$ & $1, .9$ & $r, \wedge)$ & $\cdot, V Y$ & $1, \wedge \varepsilon$ & 0 & وأهمية نرشيده المائي \\
\hline$\cdot, \vee Y \wedge$ & .,0T. & $\cdot, \ldots l$ & ᄉ, & $\cdot, \wedge$. & r,or & $1, \cdot 1$ & 1,07 & 0 & ترشيد الطاقة \\
\hline . 9 \% & $\cdot, 107$ & $\cdot, \ldots l$ & $|1,0|$. & $r, \cdot v$ & ri, ro & $1,9$. & ג, ג & r. & إجمالي الأداء \\
\hline
\end{tabular}

يتضح من الجدول السابق للفروق بين متوسط درجات النطبيق القبلي ومنوسط درجات



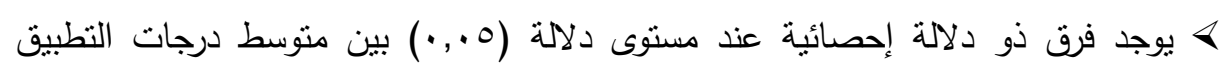



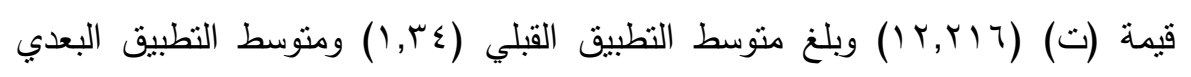

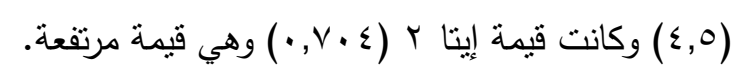

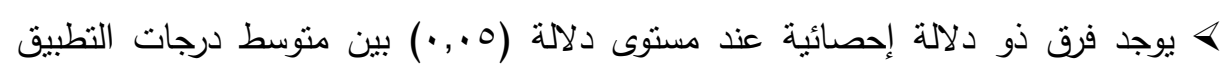

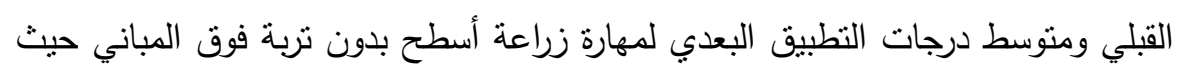






ك يوجد فرق ذو دلالة إحصائية عند مستوى دلالة (0.,·) بين منوسط درجات التطبيق

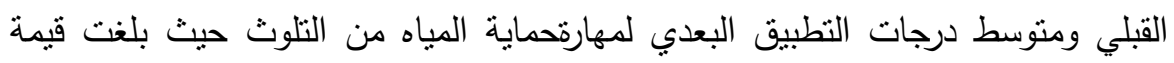

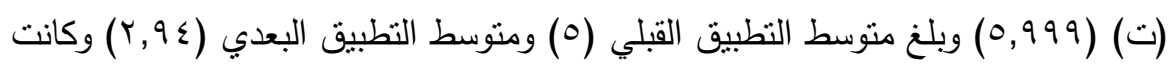

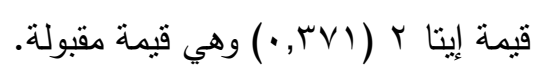

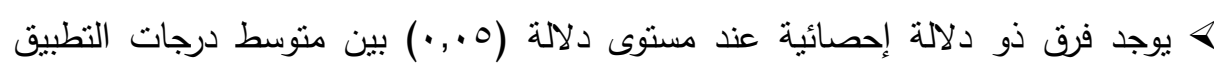

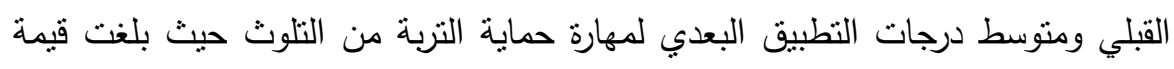

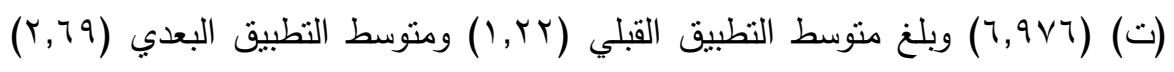

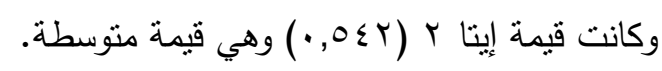

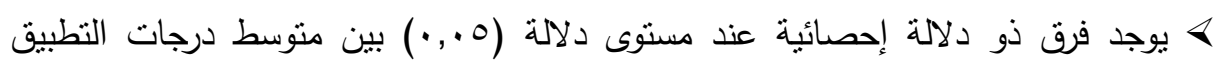

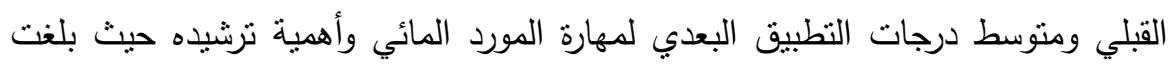

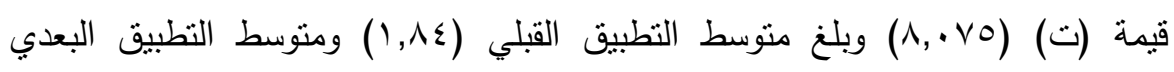

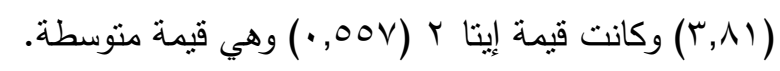

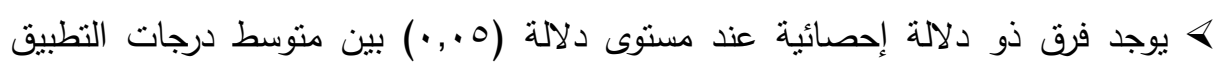

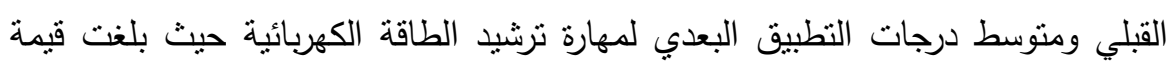



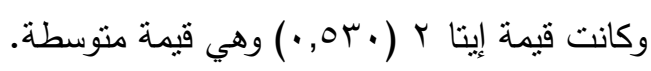



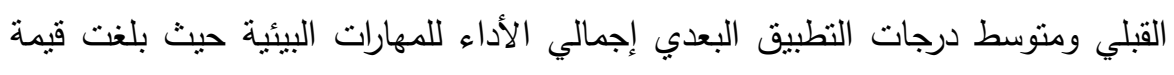

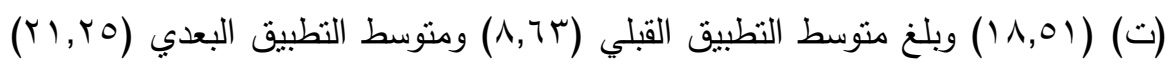






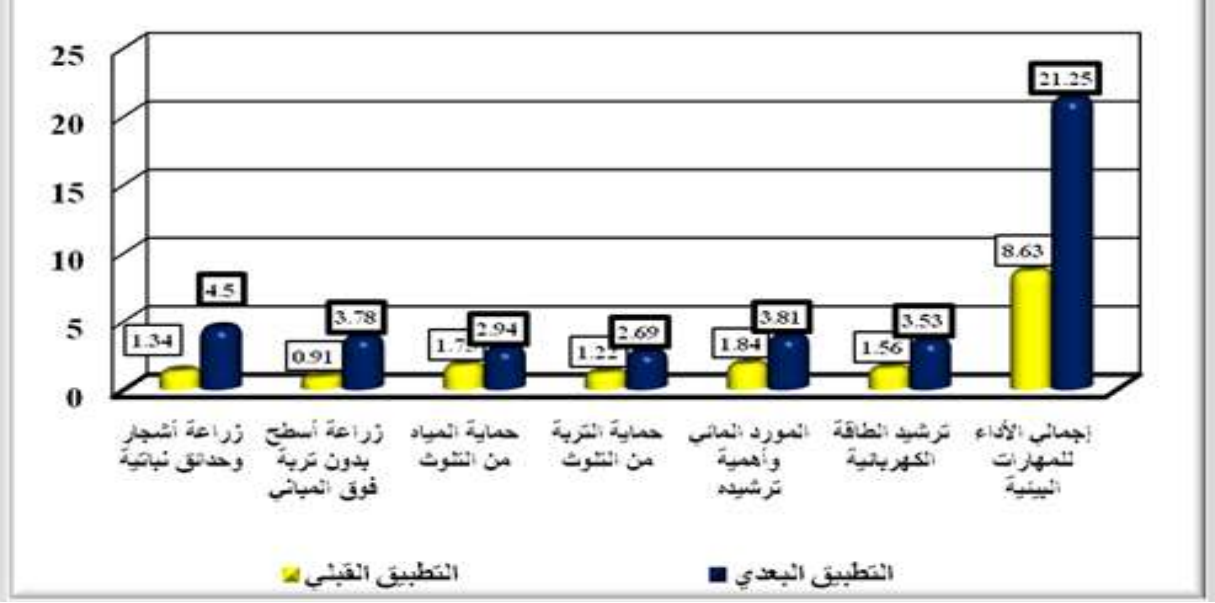

شكل (ץ): يوضح الفروق بين منتسط درجات التطبيق القبلي ومتوسط درجات التطبيق البعدي لبطاقة ملاحظات الأداء للمهارات البيئية لعبينة الإناث

من النتائج السابقة تبين صحة الفرض الثالث: توجد فروق ذو دلالة إحصائية بين متوسط درجات التطبيق القبلي ومتوسط درجات التطبيق البعدي لبطاقة ملاحظات الأداء للمهارات البيئية للذكور والإناث.

\section{الميوسيايت}

ا-ضرورة مراعاة عملية تقييم البرامج التي تمارسها المنظمة الكثفية العربية في تتمية المهارات. r-العمل علي الحد من المعوقات التي تقلل من فاعلية هذه البرامج.

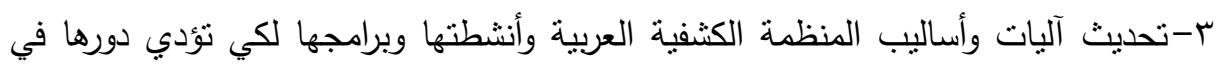
تتمية المهارات الإجتماعية والبيئية. ع-ضرورة المساهمة في جمع المزيد من المعرفة العلمية لفهم دور منظمات المجتمع المدني في تتمية المهارات الإجتماعية والبيئية لدي الثباب في تتمية البيئة التي يعيثون فيها. ه-ضرورة وجود مؤشرات لقياس نتائج وفاعلية المنظمات في مجال تتمية المهارات الإجتماعية والبيئية للثباب في العمل البيئي. 
1-تفعيل قيم المشاركة والعمل الجماعي والاتصال في شكل برامج وأنشطة تتفق وطبيعة ومسنوي نضج الثباب في سنوات العمر المختلفة.

V- العمل على توعية الثباب نحو الإستغلال الأمتل للموارد والإمكانيات المتوفرة في البيئة.


تقدمها منظمات المجتمع المدني لتتمية المجتمع المحلي متل الحفاظ على البيئة ونظافتها.

\section{المرام}

أحمد مصطفي خاطر (.99 (1): الإدارة وتقويم مشروعات الرعاية الإجتماعية،الإسكندرية،

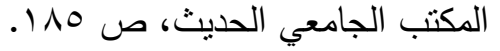

السياسة الكثفية العالمية للبرنامج الكثفي (10 بـ): المكتب الكثفي العالمي، تم الترجمة بالإقليم الكثفي العربي. العيرجي

المجلس القومي للخدمات والتتمية الإجتماعية: القاهرة، " تقرير عن دور المعكرات في تربية



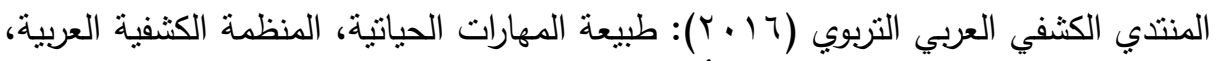



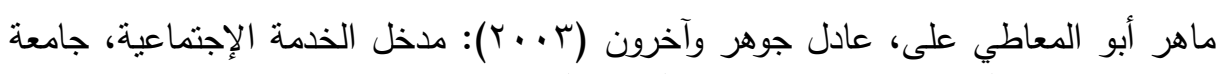
حلوان، مركز نشر وتوزيع الكتاب الجامعي.

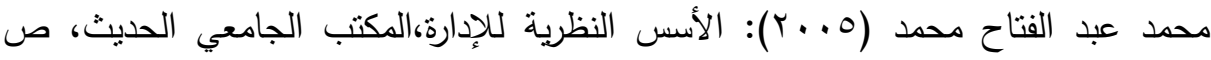
.rq

محمد عبد المنعم عبد العاطي محمد (11) ب): إستراتيجية مقترحة للحركة الكثفية المدرسية بجمهورية مصر العربية، رسالة دكتوراه، كلية التربية الرياضية، جامعة التية حلوان.

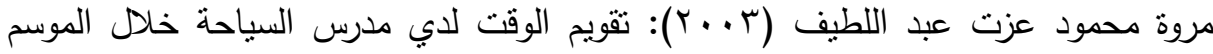



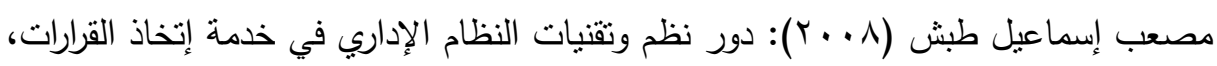

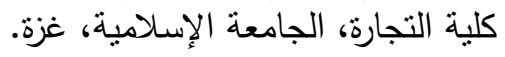


نصيف فهمي منقريوس ( . . †): ممارسة العمليات المهنية في العمل مع الجماعة، دراسات

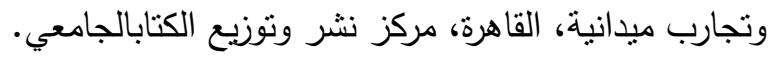

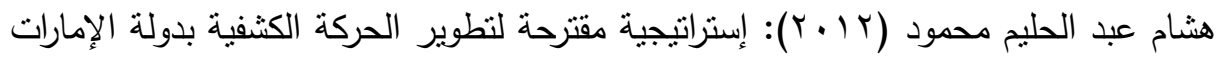
العربية المتحدة، رسالة دكتوراه، كلية التربية الرياضية، جامعة الإسكندرية.




الإجتماعية، جامعة حلوان.

Grounded-theory research on motivational development in organized youth programs, development phychology vol. (1), Jan 2011, pp.259 - 269.: Dawes , Nickki Pearce.

Jimenez, Agueda parka and others (2009): Promoting positive youth development the extracurricular activities، papeles Del psicologo, vol. 30(3).

Park, Gloria H. (2011): the role of extracurricular activity in positive youth development, dissertation, abstracts international, vol. 71 (11- B). 
مجلة العلوم البيئية

معهد الدراسات والبحوث البيئية - جامعة عين شمس لئس

\title{
EFFECTIVENESS OF A PROPOSEAL PROGRAM TO \\ DEVELOPMENT OF SOCIAL SKILLS AND \\ ENVIRONMENTAL FOR YOUTH \\ FIELD STUDY OF ARAB SCOUTS \\ ORGANIZATION'S
}

[10]

\author{
Wael M. R. Abdo ${ }^{(1)}$;Hatem A. Ahmed ${ }^{(2)}$ \\ Moheb M. k. ELRafii ${ }^{(2)}$ and Atef Abdel Meguid ${ }^{(3)}$ \\ 1) Ministry of Environment 2) Institute of Environmental Studies \& \\ Research, Ain Shams University 3) The Arab Scout Organization.
}

\begin{abstract}
The present study aimed at developing the social and environmental skills of the youth of the Arab Scout Organization, as well as the contribution of the Arab Scout Organization to achieving its objectives in serving the environment through a proposed program. Interviews with a number of mobile people and also through attending conferences and workshops in the Arab Scout Organization. Some observations were drawn. The most important of these were the lack of scouting programs to use the skill of time management, teamwork and communication, The appropriate strategy to confirmandstrengthen, In view of the importance of afforestation skills and the preservation of the environment and the rationalization of the consumption of water, food and electric energy for the protection of the environment, a program was developed to develop social and environmental skills for youth members of the Arab Scout Organization. The study used the descriptive analytical method. The study tools were a note card and a questionnaire. The sample of the study was the members of the Arab Scout Organization in Cairo (75) youth during the period 2017/2018.
\end{abstract}




The research tools were applied to the members of the research group (experimental and control) before and after the application of the program.

The results of the research resulted in the effectiveness of the proposed program in developing the skill of time management, teamwork and communication skills. Therefore, the research recommended the importance of developing the skill of afforestation, Consumption of water, food and electrical energy for the protection of the environment. 